\title{
Social Protection for Orphaned and Vulnerable Children in Kenya: Initiatives, Opportunities and Challenges
}

\author{
Joseph Misati Akuma \\ Universite de Pau et des Pays de l'Adour, France \\ josephmisati (at) yahoo.com
}

Abstract

\begin{abstract}
HIVIAIDS, conflicts and other crises have swelled the number of OVC's in sub - Saharan Africa, thereby threatening the realization of the Millennium Development Goals in the areas of Education, Health, Nutrition, and Poverty reduction. In Kenya, Social Protection is explicitly prioritized in Vision 2030, the newly promulgated Constitution of Kenya 2010 and in the National Affirmative Action Policies. Between 2005 and 2010, expenditure on Social Protection rose from Ksh. 33.4 billion to Ksh57.1 billion, which is equivalent to 2.28 per cent GDP. The above notwithstanding, discourse analysis involving a critical review of existing literature indicates that Poverty and vulnerability remain high in the country. Hence, clearly, there exists knowledge gaps on the response to the OVC situation, and in Particular, the impact of the various Policies and strategies aimed at interventions for the welfare of OVC's in the country. This paper attempts to synthesize current knowledge on the models and practice of policies targeting OVC's in Kenya with a view to bringing out discontinuities in order to inform future initiatives, especially those emerging from the framework of the newly promulgated constitution. Data was obtained mainly from secondary sources including: Sessional Papers, National Development Plans and Statistical abstracts. It is recommended that: Development of a Management Information System to capture information about OVC's, Strengthening Community Based support systems, Mainstreaming social protection in the programmes of all Government Ministries as opposed to the current six, Providing training and facilitation alongside the financial means to care - givers in vulnerable families, Prioritizing provision of Psycho -social support in addition to the material support currently offered, and reflecting OVC as a priority special needs in all sectoral policy planning and strategy process will go a long way in guarding against the escalating crisis of the vulnerable children which threatens to tear at the very fabric of childhood.
\end{abstract}

Key Words: Childhood, Vulnerable Children, Social Protection, Social Policy, Social Action, Vision 2030

\section{Introduction}

Orphan hood and Vulnerability pose numerous challenges to the wellbeing of children globally (World Bank, 2004; Patterson, 2005; Kumara et. al, 2011) and is recognized as an issue with Social, economic, and human rights dimensions (Biemba et. al, 2009). In sub- Saharan Africa where HIV has spread rapidly, both the percentage and the absolute number of children who are orphans are rising dramatically (Mwakalobo, 2007; Hunter, 2003). The region has the highest rates of absolute poverty in the world; hence, the probability of not attaining the Millennium Development Goals is particularly high for the continent's countries experiencing the risk. Moreover, the region has the highest rates of absolute child poverty in the world (Gordon. et. al, 2003; Barrientos et. al, 2005)

In Kenya, children under the age of 14 years constitute $42.9 \%$ of the estimated 38.9 Million People, while those aged 18 years and below stand at 16.9 Million (Kenya, Republic of, 2009; PBR, 2012).Despite the children representing a significant majority of the country's population; they are the most vulnerable group. A Rapid assessment, Analysis and Action planning process conducted Kenya in 2004 found that 1.8 Million children were orphans having lost one or both parents (Kenya, Republic of, 2004) with nearly $25 \%$ of them living in extreme poverty.

According to the National Aids Control Council (NACC) there were additional 600,000 children who were not orphans, but vulnerable, as their safety wellbeing and development are threatened (NACC, 2008).

The newly Promulgated constitution of Kenya contains a comprehensive bill of rights in which Article 43 guarantees all Kenyans economic, social and cultural rights. It asserts the "right for every person to social security and binds the State to provide appropriate social security to persons who are unable to support themselves and their dependants (Kenya, Republic of, 2010).

Childhood in Kenya is largely defined by the fact that over $50 \%$ of Kenyans live in absolute poverty, which means that many children live below the poverty line. The Plight of the children is at stake, with the number of vulnerable children expected to rise dramatically in the coming decades. The drivers to the vulnerability have been attributed to among others HIVIAIDS pandemic and the rising poverty levels. 
ISSN 2411-9563 (Print) ISSN 2312-8429 (Online)
European Journal of Social Sciences Education and Research
September-December 2014

Volume 1, Issue 2

\section{Factors associated with child vulnerability in Kenya}

As already pointed out, HIVIAIDS accounts for the major humanitarian crisis for families in the African Continent. Despite the two decades of its control and prevention on the African continent, its spread continues unabated (O'Manique, 2004). Over and above the colossal personal suffering, the dire Social and economic consequences for fragile Nation states such as Kenya are unbearable, not only in health but also in Education, Industry, Agriculture, Human Resources and Social welfare provision in general (Poku et.al, 2007).

The Kenya AIDS indicator Survey (2007) estimates the average HIV prevalence among the general population aged 1549 at $7.4 \%$ while the KDHS 2009 estimated the prevalence for the same population at $6.3 \%$ (KDHS,2009). It is estimated that more than 2.4 Million children are Orphans and half of them are due to HIVI AIDS. Besides depriving the children of their basic needs and exposing them to extreme vulnerability, AIDS increases the risk that the children will end up in the streets, where they will be sexually abused or infected with HIVIAIDS or caught up in criminal activities.

Secondly, the magnitude and expansion of poverty in Africa and the grave threat that it poses to social, political, and economic stability make it one of the greatest challenges facing the region (Kankwenda et al, 2000). According to Ainsworth (2002), there is a well-established link between poverty and Vulnerability. While situations vary from country to country, the poverty situation is influenced by a wide range of factors, including; Poor people's lack of access to income earnings and productive activities and essential social services (Health, Education, Safe water, and clean environment). Their low level of participation in political processes and their lack of influence on the political life of their countries and the indirect consequences of external economic and financial actors over which African countries have no control. Furthermore, even where governments have drawn up general policy guidelines on poverty reduction, problems and lack of progress persists. Poverty remains high in Kenya despite the government's efforts to address it over the last four decades.

In Kenya, as elsewhere in Africa, poor people have little if any say in government decisions that affect them or in choice of services designed for them and poverty reduction policies continue to be Top-down. Compared to other regions of the world, Africa has the highest incidence of children at risk of poverty, disease, malnutrition, mortality and orphan hood (Kempe, 2008). Poverty is the primary cause of child vulnerability. It results to inadequate access to basic goods and services (Hope, 2004)

The poverty has tended to impact more on those who cannot generate an income or access livelihoods independently, such as orphans and vulnerable children, child headed households, older persons and people with severe disabilities. The Kenya Government has committed itself to the attainment of Millennium Development Goals, beginning with the implementation of the Economic Recovery Strategy for employment and wealth creation ERS, 2003- 2008 and presently The Vision 2030, being implemented through five year medium - term plans, with the first one covering the period 20082012.More specifically, there is proposal to establish a social protection policy on the most vulnerable members of the society.

\section{The OVC Policy initiatives in Kenya}

Kenya has a long history of investing in social protection and was one of the first countries in the region to develop a National plan of action to address the needs of children without parental care (IATTCHAWGNPLA, 2008). However, prior to 2003, when the NARC Government took over the country's leadership, the main form of safety net support offered to the poor and the vulnerable populations was in form of humanitarian relief in response to crises.

In the 1990's, when it was realized that the Structural Adjustment Programmes were increasing the vulnerability of certain groups, social safety nets intended to provide targeted income support and access to basic social services to the poorest population groups were introduced.

As a consequence of the ratification of the convention of the rights of the child (CRC), the Convention on the elimination of all forms of discrimination against women and other international conventions relating to women and children, the Kenya government embarked on extensive reforms relating to women and children. Soon after the ratification of the CRC, the Attorney- General directed the Kenya Law Reform Commission (KLRC) to hasten the review of laws pertaining to children, a process which had begun in 1984 when KLRC was established. The Commission established a multi-disciplinary task force which commenced its work in 1991, preparing a draft children's bill - 1993.

The enactment of the children's Act, an initiative that sought to consolidate primary laws dealing with children, makes extensive provisions on the right of the child as enshrined in the international instruments, including protection against 
Physical, sexual and Psychological Violence. The Act establishes statutory structures to facilitate the administration of and safeguard the rights of children, including the creation of the National Council for Children Services (NCCS), a body cooperate whose general mandate is to exercise general supervision and control over Planning, financing and coordination of child rights and welfare activities.

As already pointed out, Kenya was one of the first countries in Sub - Saharan Africa to carry out a RAAAR in order to quantify the OVC situation, which eventually led to the development of the National Plan of Action for OVC's 2007-2010. Published in 2009, the NPA includes policies and guidelines on OVC intervention in the country. The first priority area in the strategy is strengthening the capacity of families to care for OVC at the household level (Kenya, Republic of, 2009). In an attempt to provide systematic support for OVC by strengthening the households to take care of OVC, the Kenyan Cash Transfer (CT-OVC) was inaugurated in 2005.

Initially, the Program roll - out began at three pilot districts in 2004 with 500 households and expanded to 37 districts by June 2008 covering 25,000 beneficiary households and by end 2011 , it had evolved to become the largest social protection program in Kenya covering 125,000 households inhabited by 350,000 OVC's .

\section{The impact of Social Protection Programmes on OVCs in Kenya}

Numerous studies carried out to examine the effects of the CT- OVC programmes in Kenya show that the programme has had far reaching impacts on household welfare. For instance, there has been a significant increase in household consumption, reduction of on-farm child labour and significant positive impact on enrolment of children in secondary schools (Bryant, 2009; Davis et. al, 2012,).At primary school level (with primary enrolment as programme indicator), although no much sensitivity has shown (The insensitivity is attributed to another programme i.e. FPE which had already made this free at the point of entry), enrolment has increased for small households. Truancy is also seen to be declining and beneficiaries report primary school children being send home for school fees is less. In terms of other aspects of Human Capital Development- a major goal of the CT-OVC programme - Improvements in health and retention of OVCs within the households and communities and childcare behavior change have been attained. Additionally, there has been inclusion of community voice in targeting, with local OVC Committees comprising community leaders, among others overseeing community validation of targeting of targeting lists hence increasing transparency and reducing suspicion of bias or corruption in selection of beneficiaries(Jackson et al,2011).

Lastly, there is evidence to indicate that the poverty targeted cash transfer programme in Kenya has helped reduce HIV risk among Orphans and Vulnerable Children (Handa et. al, 2012)

\section{Policy Implementation Gaps and Challenges}

Kenya has clearly made strides to ensure, at policy level, a coherent framework for social protection. Furthermore, the numerous Sector review exercises clearly demonstrate the political will and the government's commitment to expanding both qualitatively and quantitatively the childrens' access to social protection as outlined in the Country's Bill of Rights ( Kenya, Republic of,2010). The Development of a National Social Protection Policy (NSPP) which was recently ratified by the cabinet, with the aim of progressively expanding coverage of social security in line with the Government's constitutional commitment is a clear attestation to this fact. The above notwithstanding, there clearly exists glaring policy and implementation gaps as shown in the preceding discussion;

\section{a) Limited Emphasis on Psycho - social Support in National policy and implementation}

Orphan hood, including its prelude and consequences affects the Psycho- social development and wellbeing of children (UNAIDS 2004).

A study in Uganda's Rakai District to determine the nature and emotional problems of orphaned children found out that majority felt angered about their parents' death, especially those living with relatives (Sengendo.et.al, 1997) and that many of them were showing signs of stress and trauma. Orphans may experience additional trauma from lack of nurturance, guidance and a sense of attachment, which may impede their socialization process- through damaged self-confidence and motivation. When a parent dies from AIDS, Trauma is often accompanied by stigma and discrimination. At school, AIDS orphans may be singled out or rejected by their peers, which can create barriers to healthcare, education and access to social events (Subbarao et .al, 2004). 
In Zimbabwe, a study conducted to determine children's needs found out that the OVCs were worried most of the fact that they were growing up without parents $(24 \%)$, while $6 \%, 19 \%, 5 \%$, and $21 \%$ mentioned ill health, Poverty, shelter and not completing school respectively as their greatest concerns (UNICEF, 2005).Similarly in India, studies indicated that the material poverty was not the barrier most frequently cited by the affected children and their caregivers

In Kenya, though, there has been most notably the steady expansion of social cash transfer programs both in terms of geographic areas and in the number of households covered; a significant gap exists in the CT-OVC's efforts to prioritise the child's mental Health and psychological wellbeing.

\section{(b) Participation of OVC's}

Until the late 1990's Child welfare agencies treated children largely as immature, passive and vulnerable beings in need of protection and services. Adults were assumed to know what is best for children and consulting children considered a waste of time (O'Kaine et al, 2005). This view has been challenged by UNCRC and children are now regarded as active participants in society whose views should be sought and involved in decisions affecting them (Prout et. Al, 1997)

In a study in Andra Pradesh to find out barriers to OVC children's wellbeing, it emerged that the children had very little say in decisions affecting their lives and that no advice was given to them nor were their opinions sought(UNICEF,2007). In Nepal, child involvement via child clubs has enhanced self-esteem, self-confidence and awareness on a whole range of issues including child protection. The children sit and participate in local policy development and allocation of resources (Government of Nepal, 2006).

In Kenya, although the child protection system structure has been decentralized to location level, representation at the Location Area Advisory Council does not provide fair representation to the OVC's.Out of a membership of 10, only 2 slots are allocated for the children(20\%).In its goals and strategies for the first medium term plan ending in 2012, the Vision 2030 Policy document has indicated the "ensuring of adequate representation of Vulnerable groups in decision making as one of its strategies to reduce Vulnerabilities"(Kenya, Republic of , 2007 )

\section{(c) Care givers}

In Kenya, Most of the Orphans have been absorbed into the extended family networks, many of these extended family care givers are aging and often impoverished grandparents .Savings for old age in Kenya is relatively low at about 18 percent compared to over 45 per cent for comparable countries (Kenya, Republic of, 2007). The old age of many primary care givers has major implications for the future support and livelihoods. In a study investigating the experiences of family caregivers in South Africa, the respondents expressed difficulty in coping with teenage rebellion and that family care givers experience lack of welfare and family support in their care of HIVIAIDS orphans (Adetto et.al, 2005). Mechanisms for providing care and support to OVCs and their care givers by improving incomes and productivity and establishing sustainable food security systems at the household level helps to strengthen the capacity of the household's in the care for OVCs.The gradual collapse of the extended family and the compounded impact of poverty and the high HIVIAIDS prevalence rates, has already aggravated the already precarious situation of the OVC.Consequently, household food insecurity is increasingly becoming a critical problem among the most vulnerable households caring for OVC.There is therefore need to facilitate individual OVC and households with OVC to organize themselves into cooperative groups for undertaking economic activities in their communities and provide micro finance facilities.

Evidence from the CT-OVC Programme demonstrates the vital role played by caregivers (the majority of whom are women). Despite legal guarantees of ownership rights, Kenyan women continue to have unequal access to productive assets due to patriarchal customs, hindering the potential for asset accumulation, which could help build resilience in the provision for OVCs in Kenya.

\section{Recommendations for policy}

Generally, Child vulnerability presents a significant and pressing development challenge in Kenya but existing evidence suggests that social protection initiatives for vulnerable children have had a mixed impact at best and that there is significant potential for programme implementation modifications if genuine transformation in children's lives is to be achieved. In particular, the following key areas need to be prioritized; 
1) Promoting greater focus on women's and caregivers wellbeing. Including complementary programmes to help address other sources of vulnerability such as skills training for income generation, access to gender based violence prevention and redress services and support in forming savings and credit associations. In addition it is imperative to strengthen community based support systems by building on existing community structures such as women and church groups.

2) Prioritize provision of psycho- social support as the greater need for OVC is psychological wellbeing and mental health of the affected OVC's.A significant gap in the CT- OVC programme is the absence of efforts to train households and strengthen families.

Pervasive anxiety, sadness, fear and hopelessness among children and adolescents during their parents' AIDS related illness and death, and subsequently in orphan hood. Currently, the greater focus is on material needs at the expense of the psychological needs of children.

3) There is urgent need to reflect OVC as a priority special needs group in all sectoral policy, planning and strategy process, just as children with disability are catered for in such processes

4) Kenya's Social protection programmes are heavily dependent on international donors. Despite the greater policy commitment by the government over the last decade, the bilateral multilateral agencies are responsible for contributing $88 \%$ of all funding (Aston et al, 2012). There is need to institutionalize the programmes within the national philosophy, policy and the budgetary system

5) Design a clear exit strategy especially for OVC's to reduce over- dependency and burden of the programmes.

6) Mainstream Social Protection in all relevant government Ministries and departments. Currently only Agriculture, Education, Lands, Health, Special programmes and Gender are actively involved.

7) Design and implement an effective Management information System not only for Capturing OVC data at all levels but also for continuous Monitoring and evaluation.

\section{Conclusion}

The foregoing review points to the fact that there are a myriad of opportunities which the country needs to capitalize on in its quest to further develop its social protection policies and programmes for OVC's. To begin with, the country can tap the existing enabling policies so far formulated to improve the welfare of its children, notably the current Master Development Blue print - Vision 2030. Similarly, there is evidence of renewed considerable interest by many bilateral and multi- lateral development partners whose contribution will go a long way in enabling the country achieve its targets aimed at achievement of Vision 2030, the ratified and locally domesticated international instruments and the Millennium Development Goals.

\section{References}

[1] Adetto.M, Kadiyala, S, Roopnaraine, T; Biermer- Jenzano, P \&Norman, (2005) Children in the Shadows of AIDS: Studies of Vulnerable Children \& Orphans in three Provinces in South Africa. Washington, D.C- U.S.A, International food Policy research Institute

[2] Ainsworth, M; Filmer, D (2002) Poverty, AIDS and Children's Schooling: A targeting dilemma. Policy Research working Paper 2885.Washington, D.C: World Bank.

[3] Aston, T and Nicola (2012) Social Protection and Child malnutrition: Kenya. Overseas Development Institute and Save the Children. UK

[4] Barrientos, A and Hulme, D (2005) Chronic Poverty and Social Protection: Introduction. In the European Journal of Development Research.Vol.17 No.1. March, 2005. PP

[5] Biemba,G; Njoka,J; Simon, J; Costello; Beard \& Brooks, B (2009) Kenya Research situation analysis on orphans and other vulnerable children. Boston University Centre for global Health \& Development. Boston

[6] Bryant, O.John (2009) Kenya's cash transfer programme: Protecting the health and human rights of orphans and vulnerable children. Health and Human right: An International Journal. Vol 11.No.2. 2009. 
[7] Colleen O'Manique (2004) Neo- Liberalism and AIDS crisis in Sub Saharan Africa: Globalization's Pandemic. Palgrave, Macmillan.

[8] Davis, B; Gaarder, M; Hander, S; Yablonski, J (2012) Evaluating the impact of Cash transfer programmes in sub Saharan Africa: An introduction to the special issue. Journal of Development studies.Vol 4:No.1, PP.1-8

[9] Fox, L; Liebenthal, R (2006) Attacking Africa's poverty: Experince from the ground. The World Bank. Washington D.C

[10] Gordon, D.S; Nandy, C; Pantazis, S.P \& Townsend (2003) Child poverty in the developing World. Bristol, policy Press

[11] Government of Nepal (2006) National Progress Report: "Plus5" Review of the 2002 special Session on Children and a world fit for children plan of Action. Ministry of Women, Children and social welfare.

[12] Guimaraes, R.J.R (2007) Searching for the Vulnerable: review of the concepts and assessment of Vulnerability related to Poverty. The European Journal of Development research.Vol.19 No.2, June 2007

[13] Handa,S;Halpern,C;Pettifor,A;Thirumurthy,H(2012) Impact of the Kenya Cash Transfer for orphans and Vulnerable Children program on HIV Risk behavior. Washington D.C

[14] Hlabyago, K.E \& Ogunbanjo, G.A (2009) "The experiences of family caregivers concerning their care of HIV/AIDS orphans" in S.A FAM PRACT.2009; 51(6):506-511

[15] Hope, K.R (2004) "The Poverty dilemma in Africa: Towards Policies for including the poor" progress. Progress in Development studies.4 (2):127-141

[16] Hunter, S.S (2003) who cares? AIDS in Africa. Palgrave. Macmillan: New York

[17] IATTCHAWGNPLA (2008)"National Responses for children affected by AIDS: Review of Progress and lessons learned", IATT, New York, August 2008 Pp. 11-13

[18] Jackson, C; Butters,S;Byambaa,E;Davies,M;Perkins,N( 2011) Lessons from social Protection program implementation in Kenya, Zambia and Mongolia. IDS Research Report 69

[19] Kakwenda, M; Gregoire, L.J; Legros, H; Ouedraogo, H (2000) Poverty eradication: Where stands Africa

[20] Kenya, Republic of (2009) National plan of Action for Orphans and vulnerable Children, 2007-2010.Ministry of Gender, children and Social Development. Nairobi

[21] Kenya, Republic of, (2012) Kenya Social protection Sector Review. Ministry of state for planning, National Development and Vision 2030.Nairobi (2004) Establishment of the national steering committee on Orphans \& vulnerable Children. Government printer, Nairobi 2010, Nairobi (2009) 2009 Kenya population and housing census .Kenya National Bureau of statistics (2008) National Social protection and promotion in Kenya: A presentation during the Brazil study tour for African Countries, 25th-29th August, 2009 (2007) Kenya Vision 2030 .Popular Version (2008) National plan of Action for Orphaned and Vulnerable Children. Revised Edition (2010) United Nations General Assembly Special Session on HIVand AIDS country Report - Kenya. Office of the President.NACC

[28] Kempe, R.H (2008) Poverty, livelihoods and Governance in Africa: Fulfilling the Development Promise.Palgrave, Macmillan, N.Y

[29] Kumara, S.A \& Pfau, D.W (2012) Impact of cash transfer programmes on school attendance and child poverty: an Ex Ante Simulation for Sri Lanka in The Journal of development studies Vol 47 No. 11.Nov 2011.Routledge Taylor \& Francis. Oxford

[30] Mwakalobo, B.S.A (2007) Implications of HIVIAIDS for rural livelihoods in Tanzania: The example of Rungwe District.In African Studies Review.Vol.50 NO3.Dec.2007 
[31] NACC (2008) UNGASS 2008 Country Report for Kenya. Office of the President. Nairobi

[32] Patterson, S. Amy (2005) The African state and the AIDS crisis.Ashgate Publishing Ltd. Burlington, U.S.A

[33] Poku, K.N; Whiteside, A (2007) The Political economy of AIDS in Africa.Ashgate Publishing Limited.

[34] Prout, A; James, A (1997) Constructing and Reconstructing childhood, Contemporary issues in the sociological study of childhood.2 ${ }^{\text {nd }}$ Edition.London.Falmer Press

[35] Population Reference Bureau (2012) World Population DataSheet. The Population Reference Bureau, Washington, D.C

[36] Sengendo, J; Nambi, J ( ) 1997The Psychological effect of orphan hood: A study of orphans in Rakai District. Health Transit Rev 7 Suppl: 105- 124

[37] Shisane, $O$ and Louw, J (2006) Translating research into policy: The case of orphans and Vulnerable children in South Africa. SAHARA JOURNAL, 2006(3)2: 452- 455

[38] Smith, S.M (2006) Behond the African Tragedy: Discourses on Development and the Global economy.Ashgate Publishing limited. Hampshire, U.K.

[39] Subbarao, K; Coury, D (2004) reaching out to Africa's: A framework for Public Action. The World Bank. Washington, D.C.

[40] UNAIDS (2004) "Report on the global HIV/ AIDS epidemic". Geneva. Available at: www.unaids.org/bangkok 2004/report.html

[41] UNICEF (2005) Community based support to Orphans and other vulnerable children

[42] UNICEF (2007) Children affected by HIVIAIDS in South Asia - A synthesis of current global, regional and national thinking and research. Unicef regional office for South Asia

[43] UNICEF (2009) Monitoring the Situation of Children and Women. Retrieved on 29.09 .2012 at Www.Chilinfo.Org/hiv -aids-orphansestimates.php

[44] WORLD BANK (2004) Who are the Vulnerable Children? The World Bank Policy framework. Washington, D.C 